\title{
A novel technique to avoid intraoperative giant tear slippage: the bimanual double aspiration technique
}

\author{
Javier Placeres Daban ${ }^{1}$, Daniel Artieda García ${ }^{1 *} \mathbb{D}$, Sebastian Yaluff Portilla ${ }^{2}$ and José Isidro Belda Sanchís ${ }^{1}$
}

\begin{abstract}
Background: The aim of this paper is to present a novel bimanual double aspiration technique to avoid intraoperative giant tear slippage. The major problem of giant retinal tears (GRT) surgery is the mobility of the posterior flap (slippage), which has been classically solved by the use of intraoperative perfluorocarbon liquid (PFCL). However, avoiding slippage of the posterior flap can be a serious technical challenge when the PFCL is removed, especially when a GRT circumference is $>180^{\circ}$.

Methods: Conventional three-port 23-gauge pars plana vitrectomy (PPV) plus chandelier was performed in three patients with giant retinal tears (GRT), using the "bimanual double aspiration technique" with non-contact wide field viewing systems. All surgeries were performed by the same surgeon.

Results: None of the three cases presented with a retinal slippage after the bimanual aspiration technique.

Discussion: GRT are full thickness retinal tears that extend circumferentially more than $90^{\circ}$ of the retina. Management of GRT is a challenge for the vitreoretinal surgeons because the higher risk of proliferative vitreoretinopathy (PVR), re-detachment and increased risk of retinal slippage; this last can occur intraoperative or postoperative. Retinal slippage is not uncommon but far under-reported and can lead to various complications such as hypotony, retinal folds, and may exacerbate PVR formation. We performed bimanual double aspiration technique to avoid intraoperative giant tear slippage. We believe that this maneuver may avoid slippage by drying the posterior edge of the GRT. There were no complications related with the technique, and no additional equipment was needed.

Conclusion: In summary, "bimanual double aspiration technique", is a simple, effective, safe and economic maneuver that could be a good option to avoid intraoperative slippage in giant retinal detachment surgery, thus achieving the stabilization of the posterior retinal flap.
\end{abstract}

Keywords: Retinal slippage, Retinal detachment, Retinal surgery, Giant retinal tear

\section{Background}

GRT are full thickness retinal tears that extend more than 90 degrees circumferentially of the retina [1]. Management of GRT is challenging for the vitreoretinal surgeons: they cause a higher number of proliferative

\footnotetext{
*Correspondence: artiedagarciadaniel@gmail.com

${ }^{1}$ Torrevieja Hospital, Road CV 95, s/n, 03186 Torrevieja, Alicante, Spain

Full list of author information is available at the end of the article
}

vitreoretinopathy (PVR), the retina is more prone to redetachment and increased risk of retinal slippage; this last can happen intra or postoperatively. GRT surgery may cause mobility of the posterior flap (slippage), which can be dealt by the use of intraoperative PFCL $[2,3]$. However, avoiding slippage of the posterior flap might be a serious technical challenge when the PFCL is removed, especially when GRT circumference is $>180^{\circ}$. To overcome this problem direct $\mathrm{PFCL} / \mathrm{SO}$ exchange using $\mathrm{SO}$ 
as a primary tamponade has also been described but its difficult in manipulation together considerable amount of PFCL needed, makes this technique more complex, expensive and time-consuming [4]. SO should be avoided in the eyes in macula-on GRT with no PVR with good visual potential as well. Other studies reported a twostage surgical procedure to treat GRT where PFCL were used as a short-term vitreous tamponade with good safety profile and low re-detachment rate $[5,6]$. Nevertheless, the drawbacks of this option are the multiple surgeries needed in every patient and the PFCL-related complications including raised intraocular pressure, cataract progression, and intraocular inflammation $[7,8]$.

\section{Methods}

\section{Surgical technique}

All three patients with GRT were treated with the same technique and by the same surgeon (JPD). Local Anesthesia was induced by peribulbar nerve block. Conventional three-port 23 gauge pars plana vitrectomy (PPV) plus chandelier was performed, with non-contact wide field viewing systems. Central and exhaustive peripheral vitrectomy was performed, all the vitreous traction was removed from the GRT with retinectomy of the anterior flap. PFCL was injected slowly over the posterior pole and reached the posterior border of the retinal break, subsequently draining the subretinal fluid through the original retinal break. During the fluid-air exchange, "the bimanual double aspiration maneuver" was done; simultaneous active aspiration of the PFCL bubble near the optic nerve head and passive aspiration of the subretinal fluid on the posterior border of the retinal break was done, assisted with a backflush $23 \mathrm{~g}$ cannula. Swept movements of the passive aspiration at the level of the posterior retinal flap were performed, to avoid slippage of the GRT. After complete fluid- air exchange, three to four rows of endophotocoagulation were applied around the retinal break. In cases, like swelling or thickening of GRT flap, endophotocoagulation may be performed under PFCL. SO or $14 \%$ of perfluoropropane (C3F8) was used for internal tamponade at the end of surgery. No scleral buckling was needed (see Additional file 1: Video S1, which shows the "double aspiration technique").

\section{Results}

None of our three patients had retinal slippage, and the "bimanual double aspiration technique" was a safe and simple procedure that achieved a dried posterior edge of the GRT, avoiding slippage. No additional equipment was required to complete this technique. (See Table 1).

\section{Discussion}

Avoiding retinal slippage of the GRT is a complication that vitreoretinal surgeons often have to face. There are not many intraoperative techniques described to deal with this complication, and most of them require a massive use of PFCL. We have presented three cases of GRT in which a novel maneuver (bimanual aspiration technique) succeeded in these patients.

Failure of retinal detachment surgery in eyes with GRT can be related to the inadequate tamponade to the retina by gas or $\mathrm{SO}$, which can allow fluid to seep under the edge of the tear $[2,3]$. Retinal Slippage is not uncommon but far under-reported and can lead to various complications such as hypotony, retinal folds, and may exacerbate PVR formation [3]. Slippage typically occurs during the fluid-air exchange due the presence of a wedge of aqueous in the interface between the air and the PFCL. As the exchange progresses this fluid at the posterior edge of the GRT, can be pushed posteriorly causing a curvilinear fold of the retina. It is then mandatory to obtain a complete drying of the posterior flap of the GRT during the exchange. However, a complete dryness of the fluid is hard to achieve in some cases. Therefore, some retinal surgeon recommends direct PFCL/SO exchange that is associate with less retinal slippage $[6,8]$. This technique is challenging, and a film of fluid can remain between SO and PFCL producing the slippage of the tear.

\section{Conclusion}

In summary, "bimanual double aspiration technique" could be a safe, effective, cheap and less time-consuming option to avoid intraoperative slippage in giant retinal detachment surgery, achieving a safe stabilization of posterior retinal flap.

Table 1 Epidemiologic data

\begin{tabular}{lllllll}
\hline Patient & Age & Gender & Eye & Macular estatus & Endotamponade & $\begin{array}{l}\text { Visual acuity } \\
\text { at 12 months }\end{array}$ \\
\hline 1 & 61 & Male & Right & On & Silicone oil & 0.84 \\
2 & 54 & Female & Right & Off & Silicone oil & 0.4 \\
3 & 59 & Male & Right & On & Gas & 1 \\
\hline
\end{tabular}




\section{Supplementary Information}

The online version contains supplementary material available at https://doi. org/10.1186/s40942-021-00309-5.

Additional file 1: Video S1. It shows double aspiration technique

\section{Acknowledgements}

To the Torrevieja Clinical Hospital, for lending surgical material.

\section{Authors' contributions}

JPD (main surgeon), DAG (redaction manuscript), SYP (redaction manuscript), JIBS (redaction manuscript). All authors read and approved the final manuscript.

\section{Funding}

No contribution.

\section{Declarations}

\section{Availability of data and material}

Data sharing is not applicable to this article as no datasets were generated or analyzed during the current study.

\section{Ethics approval and consent to participate}

Not applicable.

\section{Consent for publication}

Authors indicate that it has full access to the data and take responsibility for the ingrity of the data and data analysis. This paper has not been previously published and is not currently under consideration by another journal and that all authors have approved of and have agreed to submit the manuscript to this journal.

\section{Competing interests}

The authors declare that they no competing interests.

\section{Author details}

${ }^{1}$ Torrevieja Hospital, Road CV 95, s/n, 03186 Torrevieja, Alicante, Spain. ${ }^{2}$ Quirón Marbella, 22, Severo Ochoa Avenue, 29603 Marbella, Málaga, Spain.

Received: 5 February 2021 Accepted: 29 April 2021

Published online: 27 May 2021

\section{References}

1. Schepens CL, Dobbie JG, McMeel JW. Retinal detachments with giant retinal breaks: preliminary report. Trans Am Acad Ophthalmol Otolaryngol. 1962;66:471-8.

2. Chang S, Lincoff H, Zimmerman NJ, Fuchs W. Giant retinal tears. Surgical techniques and results using perfluorocarbon liquid. Arch Ophthalmol. 1989;107(5):761-6.

3. Scott UI, Murray TG, Flynn HW, Feuer WJ, Schiffman JC. Outcoes and complications associated with giant retinal tear management using perfluoron-octane. Ophthalmology. 2002;109(10):1828-33.

4. Kenneth $L$, Wong $D$. Avoiding retinal slippage during macular translocation surgery with 360 retinotomy. Graefes Arch Clin Exp Opthalmol. 2008;12:S7-10.

5. Rush R, Sheth S, Surka S, Gregory-Roberts J. Postoperative perfluoroNoctane tamponade for primary retinal detachment repair. Retina. 2002;32:1114-20.

6. Rofail M, Lee LR. Perfluoro-octane as a postoperative tamponade in giant retinal tears. Retina. 2005;19:675-9.

7. Ang GS, Townend J, Lois N. Epidemiology of the giant retinal tears in the United Kingdom: the British Giant retinal Epidemiology Eye Study (BGEES). Invest Ophthalmol Vis Sci. 2010;51(9):4781-7.

8. Mathis A, Pagot V, Gazagne C, Malecaze F. Giant retinal tears: Surgical techniques and results using perfluorodecaline and silicone oil tamponade. Retina. 1992;12:7-10.

\section{Publisher's Note}

Springer Nature remains neutral with regard to jurisdictional claims in published maps and institutional affiliations.
Ready to submit your research? Choose BMC and benefit from:

- fast, convenient online submission

- thorough peer review by experienced researchers in your field

- rapid publication on acceptance

- support for research data, including large and complex data types

- gold Open Access which fosters wider collaboration and increased citations

- maximum visibility for your research: over 100M website views per year

At BMC, research is always in progress.

Learn more biomedcentral.com/submissions 